\title{
The evaluation of risk factors for failed response to conservative treatment in tubo-ovarian abscesses
}

\author{
Mehmet Özgür Akkurt ${ }^{1}$, Serenat Eris Yalçın ${ }^{1}$, İtaç Akkurt ${ }^{2}$, Burak Tatar ${ }^{1}$, And Yavuz', Yakup Yalçın ${ }^{1}$, Mehmet Akif Akgül ${ }^{3}$, \\ Fulya Kayıkçıŏglu \\ ${ }^{1}$ Department of Gynecology and Obstetrics, Süleyman Demirel University Faculty of Medicine, Isparta, Turkey \\ ${ }^{2}$ Department of Gynecology and Obstetrics, Isparta Maternity and Children's Hospital, Isparta, Turkey \\ ${ }^{3}$ Department of Gynecology and Obstetrics, Etlik Zübeyde Hanim Women's Health Research Hospital, Ankara, Turkey
}

\begin{abstract}
Objective: The aim of our study is to assess the risk factors for medical treatment failure and to predict the patients who will require the surgical therapy as well as to predict the factors affecting treatment success.

Material and Methods: This was a cross-sectional study including 76 women with tubo-ovarian abscesses (TOA) who were either conservatively or surgically treated and were admitted to two gynecology units over a 4-year period. The demographic characteristics of the patients, gynecologic and obstetric histories, size and localization of abscesses were recorded. Gentamicin plus clindamycin treatment protocol was implemented for all patients. Ampicillin treatment was added in three patients with the positive culture of Actinomyces. Response to treatment was evaluated after 48-72 h. Patients who fail to respond to medical treatment required surgery or percutaneous drainage. We compared clinical and laboratory factors between the groups.

Results: In surgery group, patients were significantly older than the others ( $44.9 \pm 5.4$ versus $39.1 \pm 7.6$ years). Fifty-six patients (74\%) responded to antibiotics and 20 of the patients required surgical intervention. Patients treated with antibiotics were hospitalized for an average of $6.32 \pm 2.8$ days versus $12.75 \pm 5.6$ days for those who required surgery $(\mathrm{p}=0.021)$. Patients who were surgically treated had a mean size of TOA of $67.9 \pm 11.2 \mathrm{~mm}$ versus $53.6 \pm 9.4 \mathrm{~mm}$ for those treated with antibiotics alone $(p=0.036)$. There were no significant differences between groups in laboratory parameters, except for initial white blood cell (WBC) counts. The complications of surgery included in descending order of frequency blood transfusions, surgical wound infections, bowel injury, and bladder injury.

Conclusion: An increased size of pelvic mass, higher initial WBC counts, advanced age, and smoking were all associated with failed response to conservative treatment. It is important to identify the risk factors to distinguish patients who will respond to antibiotic therapy and those who will need a surgical treatment. Thus, the required early intervention can result in a reduction in the morbidity associated with TOA.

(J Turk Ger Gynecol Assoc 2015; 16: 226-30)

Keywords: Antibiotic therapy, pelvic abscess, surgery, tubo-ovarian abscesses
\end{abstract}

Received: 01 July, $2015 \quad$ Accepted: 06 August, 2015

Available Online Date: 02 November, 2015

\section{Introduction}

Tubo-ovarian abscesses (TOA) are characterized by a walledoff inflammatory mass involving adnexa. It is a consequence of advanced pelvic inflammatory disease (PID) in almost all cases, including diverticulitis, appendicitis, inflammatory bowel disease, and gynecologic or obstetric surgery, and rarely occurs after pelvic surgery (1). Risk factors for TOA are similar to those of PID such as multiple sexual partners, presence of intrauterine devices, history of PID, and immunosuppression (1).

Most of the women with TOA are at their reproductive ages; thus, the primary aim of management is to be as conservative as possible. TOA still carry a risk of mortality, but its incidence dramatically decreased because of the new generation of antibiotics and tools for early diagnosis. However, the morbidity associated with TOA remains significant with complications including infertility, ectopic pregnancy, chronic pelvic pain, pelvic thrombophlebitis, and ovarian vein thrombosis (2). The optimal treatment regimen for TOA is less clear. Treatment modalities include intensive antibiotic therapy, minimally invasive drainage procedures, invasive surgery, or a combination of these interventions. Although TOA mostly respond well to medical treatment, approximately $20 \%-25 \%$ of patients require surgical procedures, including laparotomy or laparoscopy with drainage of abscess, unilateral or bilateral salpingo-oophorectomy, and hysterectomy (3). However, surgery for TOA is often technically difficult and associated with complications.

The aim of our study is to predict the patients who will require surgical therapy as well as the factors affecting treatment success. This study may contribute to create objective criteria to predict the need for operational intervention. 


\section{Material and Methods}

This was a cross-sectional study including 76 women with TOA who were either treated conservatively (group 1) and surgically (group 2) and were admitted to two gynecology units over a 4-year period. The study was subject to local ethics committee's approval, and written informed consent was obtained from patients who participated in this study. All authors and the study protocol have complied with the World Medical Association Declaration of Helsinki regarding the ethical conduct of research involving human subjects. In this study, some of the following tests were conducted in case of a suspicion of TOA: gynecologic examination, physical examination, erythrocyte sedimentation rate (ESR), white blood cell (WBC) count, C-reactive protein value (CRP), and ultrasound and microbiological studies from vaginal swab sampling. TOA was diagnosed in patients with abdominal pain, cervical mucopurulent discharge, cervicaladnexal tenderness on examination, and one or more of minor criteria such as fever, leukocytosis, and presence of ultrasonographic (Logiq and Voluson, General Electric, Tiefenbach, Austria) findings such as a complex mass with irregular walls, partitions, and internal echoes. The demographic characteristics of the patients, gynecologic and obstetric histories, and the size and localization of abscesses were recorded. Specimens from vagina were cultured in aerobic, anaerobic, and Thayer-Martin mediums. Pap smear test was performed for all patients.

Gentamicin was administered to all the patients [loading dose intravenous ( $2 \mathrm{mg} / \mathrm{kg}$ of body weight), followed by a maintenance dose $(1.5 \mathrm{mg} / \mathrm{kg}$ ) every $8 \mathrm{~h}$ ] (Genta; I.E Ulagay Medical, Istanbul, Turkey) plus clindamycin (900 mg IV every $8 \mathrm{~h}$ ) (Cleocin; Pfizer Inc., New York, USA) treatment protocol according to the recommendation of the Center for Disease Control and Prevention (4). Ampicillin (Duocid; Pfizer Inc., New York, USA) treatment was administered to three patients with the positive culture of Actinomyces. Response to treatment was evaluated after 48-72 h. Patients who fail to respond to medical treatment required surgery or percutaneous drainage. The criteria used to determine the failure of treatment were as follows: 1) persistent fever $\left(>38.2^{\circ} \mathrm{C}\right), 2$ ) enlarging pelvic mass, 3 ) persistent or increased abdominopelvic tenderness, 4) persistent or further elevation of WBC count, and 5) signs of sepsis such as arterial hypotension [systolic blood pressure (SBP) of $<90 \mathrm{mmHg}$, mean arterial pressure of $<70 \mathrm{mmHg}$, or an SBP decrease up to $>40 \mathrm{mmHg}$ in adults or less than two standard deviations below the normal value based on age], arterial hypoxemia [arterial oxygen tension $\left(\mathrm{PaO}_{2}\right) /$ fraction of inspired oxygen $\left[\mathrm{FiO}_{2}\right]$ of $<300$ ), acute oliguria (urine output of $<0.5 \mathrm{~mL} / \mathrm{kg} / \mathrm{h}$ for at least $2 \mathrm{~h}$ despite adequate fluid resuscitation), creatinine increase up to $>0.5 \mathrm{mg} / \mathrm{dL}$ or $44.2 \mu \mathrm{M} / \mathrm{L}$, coagulation abnormalities [international normalized ratio (INR) of $>1.5$ or activated partial thromboplastin time [aPTT] of $>60 \mathrm{~s}$ ), thrombocytopenia (platelet count of $<100,000 \mu \mathrm{L}$, tachypnea, respiratory rate of $>20$ breaths/min, heart rate of $>90$ beats/min or more than two standard deviations above the normal value depending on age, and ileus (absent bowel sounds) (5). All patients were followed up for 6 months to evaluate recurrence.

Data were analyzed by the SPSS 17.0 software (SPSS Inc. IBM, Chicago, IL, USA), and descriptive data were expressed as mean \pm standard deviations (SDs) as well as range. Chi-square and Fischer exact tests were used to analyze categorical variables and the Mann-Whitney U test was used to compare the clinical parameters of women between the groups. $\mathrm{P}$ values of $<0.05$ were considered to be statistically significant. Receivers operating characteristics (ROCs) were used to determine the threshold for age, TOA size, and WBC count.

\section{Results}

We classified the patients under medical treatment (group 1) and medical plus surgical treatment (group 2) groups. The mean age of the patients in this study was $40.34 \pm 7.4$ years. There was only one postmenopausal patient. In the surgery group, patients were significantly older than those in the other group (44.9 \pm 5.4 versus $39.1 \pm 7.6$ years). The other characteristics of the groups are given in Table 1. Forty-five patients (59\%) had intrauterine devices when TOA was diagnosed. Fifty-six patients (74\%) responded to antibiotics and 20 patients required surgical intervention (Figure 1). Patients treated with antibiotics were hospitalized for an on average of $6.32 \pm 2.8$ days versus $12.75 \pm 5.6$ days for those who required surgery $(p=0.021)$.

Vaginal cultures of 50 patients were negative; the remaining results are shown in Table 2 . There was no significant difference between groups in laboratory parameters, except for initial WBC counts (Table 3). Patients treated with antibiotics alone had lower mean WBC count than those who required surgery $(11.2 \pm 2.6$ versus $16.3 \pm 6.5 ; \mathrm{p}=0.03)$. The mean CRP level was higher in the surgery group than that in the medical treatment group. However, the difference was not significant $(p=0.4)$. Furthermore, there was no difference in ESR levels between the groups $(64.5 \pm 31.1$ versus $62.5 \pm 27.2 ; \mathrm{p}=0.84)$.

Patients who were surgically treated had a mean size of TOA of $67.9 \pm 11.2 \mathrm{~mm}$ versus $53.6 \pm 9.4 \mathrm{~mm}$ for those treated with antibiotics alone $(\mathrm{p}=0.036)$. We decided on performing

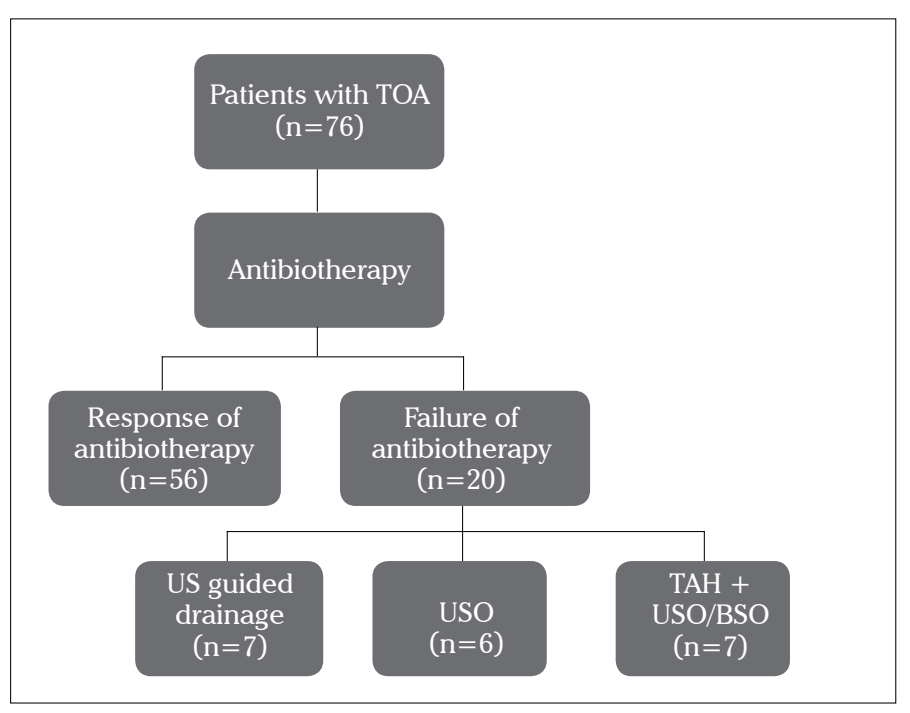

Figure 1. The flowchart showing the treatment modalities of patients with tubo-ovarian abscesses

TOA: tuboovarian abscess, TAH: total abdominal hysterectomy, USO: unilateral salpingooophoerectomy, BSO: bilateral salpingo-oophoerectomy, US: ultrasound 
Table 1. The demographic data of the patients and comparison between the two groups

\begin{tabular}{|l|c|c|c|}
\hline & $\begin{array}{c}\text { Group 1 } \\
(\mathbf{n = 5 6 )}\end{array}$ & $\begin{array}{c}\text { Group 2 } \\
(\mathbf{n = 2 0 )}\end{array}$ & $\mathbf{p}$ \\
\hline Age (years) & $\begin{array}{c}39.1 \pm 7.6 \\
(19-50)\end{array}$ & $\begin{array}{c}44.9 \pm 5.4 \\
(31-52)\end{array}$ & 0.042 \\
\hline Gravida & $3.4 \pm 2.0(0-11)$ & $4.2 \pm 1.6(2-7)$ & 0.247 \\
\hline Parity & $2.3 \pm 1.0(0-5)$ & $2.7 \pm 1.1(1-5)$ & 0.246 \\
\hline Abortion & $\begin{array}{c}0.47 \pm 0.23 \\
(0-6)\end{array}$ & $\begin{array}{c}0.50 \pm 0.29 \\
(0-2)\end{array}$ & 0.939 \\
\hline Smoking & $18(47.3 \%)$ & $8(66 \%)$ & 0.035 \\
\hline Education (>8 years) & $27(54 \%)$ & $13(50 \%)$ & 0.891 \\
\hline IUD present & $33(59 \%)$ & $12(60 \%)$ & 0.888 \\
\hline & & &
\end{tabular}

IUD: intrauterine device

Data are given as mean \pm standard deviations (range within parentheses) or percentages (frequencies within parentheses).

Group 1: patients treated conservatively, Group 2: patients treated surgically.

Table 2. The distribution of patients with positive vaginal culture among groups

\begin{tabular}{|l|l|l|}
\hline & $\begin{array}{l}\text { Antibiotic } \\
\text { therapy } \\
\text { alone } \\
(\mathbf{n}=\mathbf{1 9 )}\end{array}$ & $\begin{array}{l}\text { Antibiotic } \\
\text { therapy+Surgical } \\
\text { intervention } \\
(\mathbf{n}=\mathbf{7})\end{array}$ \\
\hline Gardnerella vaginalis & 4 & 2 \\
\hline Candida albicans & 3 & - \\
\hline Actinomyces israelii & 3 & - \\
\hline $\begin{array}{l}\text { Peptostreptococcus } \text { and } \\
\text { Bacteriodes }\end{array}$ & 3 & 2 \\
\hline $\begin{array}{l}\text { Peptostreptococcus } \text { and } \\
\text { Veillonella }\end{array}$ & 2 & 2 \\
\hline Peptostreptococcus & 2 & 1 \\
\hline Escherichia coli & 1 & - \\
\hline Staphylococcus aureus & 1 & - \\
\hline
\end{tabular}

Table 3. The comparison of laboratory parameters between two groups

\begin{tabular}{|l|c|c|c|}
\hline & $\begin{array}{c}\text { Group 1 } \\
(\mathbf{n = 5 6 )}\end{array}$ & $\begin{array}{c}\text { Group 2 } \\
(\mathbf{n = 2 0 )}\end{array}$ & $\mathbf{p}$ \\
\hline WBCs count $\left(/ \mathrm{mm}^{3}\right)$ & $\begin{array}{c}11.2 \pm 5.1 \\
(3.8-22.7)\end{array}$ & $\begin{array}{c}16.3 \pm 6.5 \\
(5.1-23.9)\end{array}$ & 0.03 \\
\hline ESR (mm/h) & $\begin{array}{c}64.5 \pm 31.1 \\
(6-118)\end{array}$ & $\begin{array}{c}62.5 \pm 27.2 \\
(16-100)\end{array}$ & 0.84 \\
\hline CRP (mg/L) & $\begin{array}{c}48.6 \pm 38.9 \\
(6-96)\end{array}$ & $\begin{array}{c}59.5 \pm 39.3 \\
(6-96)\end{array}$ & 0.41 \\
\hline
\end{tabular}

WBCs: white blood cells; ESR: erythrocyte sedimentation rate; CRP: Creactive protein

Data are given as mean \pm standard deviations (range within parentheses).

Group 1: patients treated conservatively, Group 2: patients treated surgically. surgical intervention after an average of $2.1 \pm 0.9$ days from the start of medical treatment. A total of $74 \%$ of the patients were successfully treated with antibiotic therapy alone. When surgical intervention was needed, seven hysterectomies (performed with unilateral or bilateral salpingo-oophorectomy), six unilateral salpingo-oophorectomies, and seven ultrasound-guided drainages were performed. Surgically treated patients had more complications. The most common complication encountered was blood transfusions in seven patients followed by surgical wound infections in three patients; one patient had bowel injury and the other had bladder injury. In the 6-month follow-up period, we did not observe any recurrence in both the surgical and medical treatment groups.

On analysis of the ROC curve, an age cut-off of 42.3 years was found to be optimal for predicting the need of surgical intervention with a sensitivity of $70 \%$ and a specificity of $60.7 \%$. A cut-off size of $5.7 \mathrm{~cm}$ for TOA was found to be optimal for predicting the need for surgical intervention with a sensitivity of $65 \%$ and a specificity of $80 \%$. A cut-off value of 13.6 for WBC count for predicting the need for surgical intervention was found with a sensitivity of $60 \%$ and specificity of $53.5 \%$ (Table 4 ).

\section{Discussion}

Despite the decrease in the mortality of TOA in the last decades after using broad-spectrum antibiotics as well as early diagnosis and improvement of imaging techniques, the rupture of abscess is still associated with the risk of mortality. Although the optimal treatment of TOA still remains unclear, conservative therapy should be chosen as the treatment modality as it is mostly seen during the reproductive period.

Medical management with broad spectrum antibiotics is generally considered as the initial management of TOA. When antibiotic therapy fails, surgical treatment is indicated. There remains some controversy concerning the extent and timing of operation that is appropriate for the patient requiring surgical intervention. Most of the patients with TOA are candidates for medical management. Success rates of medical treatment have been reported between $67 \%$ and $75 \%(6,7)$. In our study, surgical treatment was necessary for 20 patients (26\%). Success of medical treatment is associated with the following factors: age, abscess size, bilateral adnexal involvement, laboratory parameters (8). Failure of the medical treatment is increased in patients who had abscesses with a size of $>5 \mathrm{~cm}$; this may be because of the decreased penetration of antibiotics into the abscess cavity (911). Dewitt et al. (12) also found that TOA size is associated with important outcomes including more complications and longer duration of hospitalization as well as an increased need for surgery or drainage in patients with large abscesses as opposed to those with smaller abscesses. They found a $43 \%$ failure rate for abscesses with a size of $>8 \mathrm{~cm}$. In our study, 18 of 20 (90\%) patients who were surgically treated had abscesses with a size of $>5 \mathrm{~cm}$; the mean size of abscess was larger in the surgical treatment group.

A previous study showed that the recurrence rate of TOA following treatment with antibiotics was higher than that after surgical intervention (12). However, in our study, there had been no re- 
Table 4. Statistical analyses for prediction of the surgery following the determination of presumed thresholds

\begin{tabular}{|l|c|c|c|c|c|c|c|c|}
\hline & Thresholds & Sensitivity & Specificity & ACC & PPV & NPV & LR+ & LR- \\
\hline Age (years) & $>42.3$ & $70 \%$ & $60.7 \%$ & $63.1 \%$ & $39 \%$ & $85 \%$ & 1.78 & 0.49 \\
\hline Size $(\mathrm{cm})$ & $>5.7$ & $65 \%$ & $80 \%$ & $76.3 \%$ & $54.1 \%$ & $86.5 \%$ & 3.25 & 0.43 \\
\hline WBCs count $\left(/ \mathrm{mm}^{3}\right)$ & $>13.6$ & $60 \%$ & $53.5 \%$ & $55.2 \%$ & $31.5 \%$ & $78.9 \%$ & 1.29 & 0.74 \\
\hline
\end{tabular}

currence of TOA during the 6-month follow with regard to both medical and surgical therapies.

Karasu et al. (13) reported that the mean age of the patients who were successfully treated with parenteral antibiotics was significantly lower than that of the patients who did not respond to medical treatment (37.4 versus 43.5 years). They found 40 years as the cut-off age for medical treatment with a sensitivity of $60 \%$ and a specificity of $65 \%$. Greenstein et al. (14) also reported that older age was associated with significantly higher risk of surgery. Our results were similar to previous studies and patients who were surgically treated were older than the others. Fifteen of 20 (75\%) patients who were surgically treated were aged $>40$ years. Patients for whom fertility was no longer a matter of concern facilitated our decision in favor of surgical intervention. We did not detect a malignant tumor associated with abscess, despite a prior study that reported malignant tumors in $13 \%(2 / 15)$ of TOA patients aged $\geq 40$ years.

Osser et al. (15) suggests that the use of intrauterine device (IUD) doubles the risk of PID. Sweet and Gibbs (16) reported that the co-occurrence of TOA with IUD was approximately up to $20 \%-54 \%$. Our data also indicate an association rate of $59 \%$, which is compatible with that reported in the literature.

Previous studies reported that the prolonged duration of hospitalization was required in patients with TOA who underwent drainage or surgery $(12,13,17)$. Similarly, we found that the mean duration of hospitalization was significantly longer in patients who were surgically treated.

Laboratory evaluation in patients with TOA mostly reveals leukocytosis, increased ESR, and elevated CRP levels. Several authors have investigated the relationship between laboratory findings and the need for surgery. In a study, a higher CRP level was identified as an important indicator for surgery. However, the lymphocyte and WBC counts in the same study were not significantly elevated (17). Güngördük et al. (18) showed that CRP and ESR levels were higher in surgically treated patients. In another study, CRP and ESR levels were found to be good predictors for medical treatment failure. In this study, they found the cut-off value for CRP and ESR levels as $6.7 \mathrm{mg} / \mathrm{L}$ and $50 \mathrm{~mm} / \mathrm{h}$, respectively (13). Unlike these studies, a significant difference was not observed in CRP levels and WBC count between the favorable or poor prognosis group in the study by Topçu et al. (19). In our study, we found that there was no significant difference in CRP and ESR counts between the groups. We did not observe a relationship between these parameters and medical treatment failure. On the other hand, the initial WBC counts were significantly different between medically and surgically treated patients.

The small population sample was the limitation of our study. The results need to confirm with a larger study population. Also, prospective cohort studies will be needed to demonstrate an independent relationship across clinical and laboratory parameters as well as decision of surgical intervention.

In conclusion, increased size of pelvic mass, higher initial WBC counts, advanced age, and smoking were all associated with failed response to conservative treatment. At present, antibiotics are the mainstay of treatment for TOA. In some patients, medical treatment must be combined with operational intervention. It is important to identify risk factors to discriminate patients who will respond to antibiotic therapy or need a surgical treatment. Thus, the required early intervention can be provided to reduce morbidity associated with TOA.

Ethics Committee Approval: Ethics committee approval was received for this study from Etlik Zübeyde Hanim Women's Health Research Hospital.

Informed Consent: Written informed consent was obtained from patients who participated in this study.

Peer-review: Externally peer-reviewed.

Author Contributions: Concept - F.K., M.A.A., I.A.; Design - S.E.Y., M.Ö.A., I.A.; Supervision - F.K., A.Y.; Resource - Y.Y., B.T.; Materials - I.A., Y.Y., B.T.; Data Collection and/or Processing - I.A., M.Ö.A., A.Y.; Analysis and/or Interpretation - S.E.Y., F.K., M.A.A.; Literature Search - M.Ö.A., B.T., S.E.Y.; Writing - I.A., S.E.Y., M.Ö.A.; Critical Reviews - M.A.A., F.K.

Conflict of Interest: No conflict of interest was declared by the authors.

Financial Disclosure: The authors declared that this study has received no financial support.

\section{References}

1. Granberg S, Gjelland K, Ekerhovd E. The management of pelvic abscess. Best Pract Res Clin Obstet Gynaecol 2009; 23: 667-78. [CrossRef]

2. Wiesenfeld HC, Sweet RL. Progress in the management of tuboovarian abscesses. Clin Obstet Gynecol 1993; 36: 433-44. [CrossRef]

3. Mirhashemi R, Schoell WM, Estape R, Angioli R, Averette HE. Trends in the Management of Pelvic Abscesses. J Am Coll Surg 1999; 188: 567-72. [CrossRef]

4. Workowski KA, Bolan GA. Centers for Disease Control and Prevention. Sexually transmitted disease treatment guidelines, 2015. MMWR Recomm Rep 2015; 59: 1-137.

5. Vincent JL, Opal SM, Marshall JC, Tracey KJ. Sepsis definitions: time for change. Lancet 2013 2; 381: 774-5. [CrossRef]

6. Landers DV, Sweet RL. Tubo-ovarian abscess: contemporary approach to management. Rev Infect Dis 1983; 5: 876-84. [CrossRef]

7. Sweet RL, Schachter J, Landers DV, Ohm-Smith M, Robbie MO. Treatment of hospitalized patients with acute pelvic inflammatory 
disease: comparison of cefotetan plus doxycycline and cefoxitin plus doxycycline. Am J Obstet Gynecol 1988; 158: 736-41.

8. Halperin R, Levinson O, Yaron M, Bukovsky I, Schneider D. Tuboovarian abscess in older women: is the woman's age a risk factor for failed response to conservative treatment? Gynecol Obstet Invest 2003; 55: 211-5. [CrossRef]

9. Reed SD, Landers DV, Sweet RL. Antibiotic treatment of tuboovarian abscess: comparison of broad-spectrum betalactam agents versus clindamycin-containing regimens. Am J Obstet Gynecol 1991; 164: 1556-61. [CrossRef]

10. Ginsburg DS, Stern JL, Hamod KA, Genadry R, Spence MR. Tuboovarian abscess: a retrospective review. Am J Obstet Gynecol 1980; 138: 1055-8.

11. Mizushima T, Yoshida H, Ohi Y, Ishikawa M, Hirahara F. Evaluating the risk factors for developing resistance to parenteral therapy for tubo-ovarian abscess: a case-control study. J Obstet Gynaecol Res 2013; 39: 1019-23 [CrossRef]

12. Dewitt J, Reining A, Allsworth JE, Peipert JF. Tuboovarian abscesses: is size associated with duration of hospitalization \& complications? Obstet Gynecol Int 2010; 2010: 847041.

13. Karasu Y, Karadag B, Comert DK, Arslanca T, Kurdoglu Z, Korkmaz $\mathrm{V}$, Ergun Y. When The surgical treatment is suggested in patients with tubo-ovarian abscess? Asian J Pharm Res 2015; 5: 128-33.
14. Greenstein Y, Shah AJ, Vragovic O, Cabral H, Soto-Wright V, Borgatta L, Kuohung W. Tuboovarian abscess. Factors associated with operative intervention after failed antibiotic therapy. J Reprod Med 2013; 58: 101-6.

15. Osser S, Gullberg B, Liedholm P, Sjöberg NO. Risk of pelvic inflammatory disease among intrauterine-device users irrespective of previous pregnancy. Lancet 1980; 1: 386-8. [CrossRef]

16. Sweet RL \& Gibbs RS. Mixed anaerobic-aerobic pelvic infection and pelvic abscess. In Sweet RL \& Gibbs RS (editors). Infections diseases of the female genital tract. 4th ed. Philadelphia, USA: Lippincott Williams \& Wilkins; 2002. p. 176-206.

17. Kuo CF, Tsai SY, Liu TC, Lin CC, Liu CP, Lee CM. Clinical characteristics and treatment outcomes of patients with tubo-ovarian abscess at a tertiary care hospital in Northern Taiwan. J Microbiol Immunol Infect 2012; 45: 58-64. [CrossRef]

18. Güngördük K, Guzel E, Asicioğlu O, Yildirim G, Ataser G, Ark C, et al. Experience of tubo-ovarian abscess in western Turkey. Int $\mathrm{J}$ Gynaecol Obstet 2014; 124: 45-50. [CrossRef]

19. Topçu HO, Kokanalı K, Güzel AI, Tokmak A, Erkılınç S, Ümit C, Doğanay M. Risk factors for adverse clinical outcomes in patients with tubo-ovarian abscess. J Obstet Gynaecol 2014; 29: 1-4. 